\title{
Characterization of a Gene Identified in Pathotype 5 of the Clubroot Pathogen Plasmodiophora brassicae
}

\author{
H. Zhang, J. Feng, V. P. Manolii, S. E. Strelkov, and S.-F. Hwang
}

First author: The Institute of Vegetables and Flowers, Chinese Academy of Agricultural Sciences, Beijing, China; first, second, and fifth authors: Crop Diversification Centre North, Alberta Agriculture and Rural Development, Edmonton, AB, T5Y 6H3, Canada; and first, third, and fourth authors: Department of Agricultural, Food and Nutritional Science, University of Alberta, Edmonton, AB, T6G 2P5, Canada.

Accepted for publication 9 February 2015.

\begin{abstract}
Zhang, H., Feng, J., Manolii, V. P., Strelkov, S. E., and Hwang, S.-F. 2015. Characterization of a gene identified in pathotype 5 of the clubroot pathogen Plasmodiophora brassicae. Phytopathology 105:764-770.

Clubroot caused by Plasmodiophora brassicae is an important disease of crucifers worldwide. Isolates of the pathogen can be classified into pathotypes according to their pathogenicity on differential hosts. In this study, the presence or absence of all database-available nonhousekeeping $P$. brassicae genes (118 in total) were assessed by polymerase chain reaction (PCR) analysis in isolates belonging to five $P$. brassicae pathotypes $(2,3,5,6$, and 8 according to Williams' differential set). One gene, designated $\mathrm{Cr} 811$, was present exclusively in the isolate of pathotype 5.
\end{abstract}

ABSTRACT
This was further confirmed by dot blot hybridization and by PCR using alternative DNA preparations and primers. Reverse transcription quantitative PCR analysis indicated that in planta expression of $\mathrm{Cr} 811$ was upregulated during canola infection, especially in the stage of secondary plasmodia. Primers specific to $\mathrm{Cr} 811$ could distinguish a field isolate of P. brassicae belonging to pathotype 5 from two other field isolates representing pathotypes 3 and 8 . These findings suggest that $\mathrm{Cr} 811$ is a gene that is potentially involved in clubroot pathogenesis and that it also might serve as a molecular marker for differentiation of pathotype 5 from other pathotypes.

Additional keywords: gene expression, horizontal gene transfer, resistance, virulence.
Plasmodiophora brassicae Woronin causes clubroot disease in cruciferous plants and is an emerging threat to Canadian canola (Brassica napus L.) production (20,39). Many strategies have been proposed for clubroot control $(19,32)$, but the use of resistant cultivars is believed to be most effective (33). Breeding for resistance requires a better understanding of the virulence pattern of the pathogen population in areas where resistant cultivars are cultivated. Isolates of $P$. brassicae have been classified into pathotypes based on their reactions on differential hosts. Numerous sets of differential hosts have been proposed (39), including the commonly used differential sets of Williams (42), the European clubroot differential (ECD) (3) and the deferential set of Somé et al. (38). Based on the results of virulence testing on the differential set of Williams, pathotype 3 (P3) has been found to be predominant in Alberta (41), although P2, P5, P6, and P8 are also present $(41,43)$.

Pathotype differentiation via virulence tests on sets of differential hosts is time-consuming, labor intensive and can be affected by environmental conditions. Furthermore, due to the fact that different pathotypes may be present in single galls (22), complicated results may be obtained from such tests. Development of molecular markers specific to particular pathotypes would be a valuable tool to identify and monitor $P$. brassicae populations. For example, a random amplified polymorphic DNA (RAPD)-derived sequenced characterized amplified region (SCAR) marker specific to $\mathrm{P} 1$, as defined on the differentials of Somé et al. (38), has been developed and proven to be useful for the identification of this pathotype from field isolates (25). Our group has conducted extensive studies to characterize the

Corresponding author: S.-F. Hwang; E-mail address: sheau-fang.hwang @gov.ab.ca

*The $\boldsymbol{e}$-Xtra logo stands for "electronic extra" and indicates that one supplementary table is published online.

http://dx.doi.org/10.1094/PHYTO-10-14-0270-R

(C) 2015 The American Phytopathological Society virulence pattern of $P$. brassicae populations $(7,40,41)$ and to identify molecular markers that can be used to differentiate pathotypes.

Based on the current knowledge, the molecular determinants of a pathotype are most likely related to the presence/absence or differential expression of genes related to pathogenicity. In GenBank, there are approximately 120 nonhousekeeping genes of $P$. brassicae represented by expressed sequence tags (EST) or predicted proteins (15). In this study, 118 primer pairs specific to most of these genes were used to evaluate the presence of the corresponding genes in genomic DNA samples prepared from single-spore isolates belonging to five pathotypes as classified on the differential set of Williams (42). We hypothesized that members of these 118 genes may be specific to certain pathotypes. Thus, the objectives of this study were to (i) identify gene(s) that are deferentially present in pathotypes, (ii) molecularly characterize the identified gene(s), and (iii) test the usefulness of these gene(s) as makers to differentiate unknown pathotypes. One gene, designated $\mathrm{Cr} 811$, was identified to be exclusively present in P5. The in planta expression of this gene was studied using an infection time course on both a resistant and a susceptible canola genotype. Primers specific to this gene were used to identify P5 from field isolates. The molecular function of this gene with respect to the pathogenicity of the P5 strain also is discussed.

\section{MATERIALS AND METHODS}

Plant materials and $\boldsymbol{P}$. brassicae single-spore and field isolates. The canola cultivar Westar was used as host to maintain the $P$. brassicae single-spore and field isolates. The hybrid canola cultivars $45 \mathrm{H} 26$ (clubroot-susceptible) and 45H29 (clubrootresistant) were used in the investigation of the in planta gene expression. The differential hosts of Williams (42), consisting of the cabbage cultivars Jersey Queen and Badger Shipper and the rutabaga cultivars Laurentian and Wilhelmsburger, and the ECD set, consisting of five genotypes each of B. napus, B. rapa and 
B. oleracea (3), were used in pathotype identification of unknown isolates. Five single-spore isolates of $P$. brassicae in our collection SACAN-ss3, SACAN-ss1, ORCA-ss4, AbotJE-ss1, and CDCNss3, which are classified as P2, P3, P5, P6, and P8, respectively (43), were used in the identification of pathotype-specific gene(s). Three field isolates of $P$. brassicae derived from canola galls caused by natural infection were collected from fields in Sturgeon County, Newell County, Athabasca County, and Alberta, Canada, and classified to pathotype on the differential hosts of Williams (42) and ECD (3). To determine whether or not the presence of $C r 811$ was limited to the single-spore isolate of P5, these field isolates were subjected to PCR analysis with the Cr811-specific primers.

Preparation of resting spores. For plant inoculation, $P$. brassicae resting spores were prepared as previously described (17). Briefly, galls were homogenized in $10 \%$ (wt/vol) sucrose in a blender. The slurry was passed through eight layers of cheesecloth and the suspension was centrifuged at $50 \times g$ for $5 \mathrm{~min}$. After transfer into a new tube, the supernatant was centrifuged at 2,000 $\times g$ for $5 \mathrm{~min}$. The upper layer of the resultant pellet was suspended in $5 \mathrm{ml}$ of water by gentle pipetting and transferred into a new tube containing $40 \mathrm{ml}$ of water. After centrifugation at $2,000 \times g$ for $5 \mathrm{~min}$, the supernatant was removed. The resting spores in the pellet were resuspended in $2 \mathrm{ml}$ of water, and the spore concentration was adjusted to $1 \times 10^{7}$ spores $/ \mathrm{ml}$. The resting spores were surfacedisinfected with colistin sulfate at $1 \mu \mathrm{g} / \mathrm{ml}$ and vancomycin hydrochloride at $1 \mu \mathrm{g} / \mathrm{ml}$ at $4^{\circ} \mathrm{C}$ in the dark for $24 \mathrm{~h}$. The spores were used as inoculum after removal of the antibiotics by washing twice with $40 \mathrm{ml}$ of distilled water. For DNA extraction, the resting spores were prepared with the same protocol except that after overnight treatment with antibiotics at $4^{\circ} \mathrm{C}$, the spore suspensions were further treated at $37^{\circ} \mathrm{C}$ with 10 units $/ \mathrm{ml}$ of DNase I (Life Technologies, Carlsbad, CA) for $2 \mathrm{~h}$ to remove genomic DNA from the host plant or other organisms released into the suspension during homogenization of the galls.

Manipulation of nucleic acids. All plant and pathogen samples were ground in liquid nitrogen before nucleic acid extraction. Unless specified otherwise, $P$. brassicae DNA was extracted from the prepared resting spores following the protocol described by Feng et al. (12). DNA extraction from healthy canola roots or LB

TABLE 1. Primers used in this study

\begin{tabular}{|c|c|}
\hline Primer & Sequence $\left(5^{\prime}-3^{\prime}\right)$ \\
\hline $\mathrm{a}$ & TGGAACGTACGTAAAGGAAACG \\
\hline $\mathrm{b}$ & ATACTGTCAGAAGATGCAATCG \\
\hline $\mathrm{c}$ & TGACATTAGCGCTTCACTTGAC \\
\hline d & ATCTCGACGAGTATAGCCATAG \\
\hline $\mathrm{e}$ & TACCTGCGAACCTATGCGTGTA \\
\hline $\mathrm{f}$ & GTAAAGCTGCCGACAGAACC \\
\hline $\mathrm{g}$ & CTGTACGTCGATAACGGTCAA \\
\hline $\mathrm{h}$ & TAACGGTCAAATGGTAAGCTTCAA \\
\hline i & TCGGAAACCACACAGAGAGG \\
\hline $\mathrm{j}$ & АСTCTATATCTAGGATGCTGGAACA \\
\hline $\mathrm{k}$ & GAGCCGATCGATAACGTGAAGCAG \\
\hline 1 & AGGAGGAACCGGCAACATAGTG \\
\hline $\mathrm{m}$ & AGGATCAACAATCGGTATCATGG \\
\hline $\mathrm{n}$ & TAACGATAGCATTGCGACTCCGATC \\
\hline o & GTTCTGTGCCATGAGTGTTACAG \\
\hline $\mathrm{p}$ & GAAGCTTACCATTTGACCGTTATC \\
\hline q & CGACCTTCTTCAGGCGTAAC \\
\hline $\mathrm{r}$ & GTTATTCCGAGCGTGTACTTCTTG \\
\hline $\mathrm{s}$ & GTTATCGATCGGCTCCATCC \\
\hline $\mathrm{t}$ & AGTCCATGATACCGATTGTTGATC \\
\hline $\mathrm{u}$ & CAGTCCATGATACCGATTGTTG \\
\hline $\mathrm{v}$ & GCCGCTATTCTGATGTTATTGCT \\
\hline w & TCTTGGGTCCTTTTGAAAGTTC \\
\hline $\mathrm{x}$ & TCGTTGATGTAATCCATCTAGC \\
\hline y & TCAATGTACTCCTCGACCAAAG \\
\hline $\mathrm{z}$ & ATGTCCCTTGCGTACATGTTG \\
\hline ActF & GGGACATCACCGACTACCTG \\
\hline ActR & ACTGCTCCGAGTTGGACATC \\
\hline
\end{tabular}

$(1 \% \mathrm{NaCl}, 1 \%$ Tryptone, and $0.5 \%$ yeast extract) culture of the gall slurry, as well as from purified resting spores for Southern analysis, was performed with the CTAB protocol (35). DNA purification of PCR amplicons from agarose gels was performed using the Wizard SV Gel and PCR Clean-Up System (Promega, Madison, WI). Cloning of PCR products was conducted using the pGEM-T Easy Vector System (Promega). Sequencing was done by the Department of Biological Sciences, University of Alberta (Edmonton, AB, Canada). RNA extraction from galls or healthy roots, including the DNase I treatment, was performed using the SV Total RNA Isolation System (Promega). Synthesis of the first-strand cDNA from the purified RNA was conducted using an iScrip cDNA Synthesis Kit (Bio-Rad, Hercules, CA) or a GoTaq 2-Step RT-qPCR System (Promega).

PCR and quantitative PCR. Primers for the identification of the pathotype-specific gene(s) were derived from Feng et al. (15) with other primers used in this study listed in Table 1 . The genomic locations of the primers are illustrated in Figure 1. PCR analyses were conducted in an Eppendorf Mastercycler thermal cycler (Eppendorf, Hamburg, Germany). Except in the genome walking analysis, all PCR analyses were run in a final volume of $20 \mu \mathrm{l}$ in the Promega master mix with $0.25 \mu \mathrm{M}$ of each primer and $100 \mathrm{ng}$ of template; for all primers, the annealing temperature was $52^{\circ} \mathrm{C}$ and/or $56^{\circ} \mathrm{C}$, the elongation time was $45 \mathrm{~s}$, and the cycle number was 35 . Quantitative PCR (qPCR) assays were conducted in a StepOne RealTime PCR System (Life Technologies) using the GoTaq 2-Step RTqPCR System (Promega) for RNA analysis or the Power SYBR Green PCR Master Mix (Life Technologies) for DNA analysis. The P. brassicae Actinl gene (GenBank accession number AAR88383) was used for normalization. Primer efficiency was verified using standard curves generated from the purified PCR product of the targeted fragments. The quantity of $\mathrm{Cr} 811$ relative to Actinl, at the DNA or RNA level, was calculated via the delta-delta method, with relative expression or amount $=2^{-(\Delta C T \text { sample}-\Delta C T \text { control })}$ (36). All qPCR amplifications were performed in triplicate for each of three template preparations derived from different biological samples. Data from the qPCR were analyzed for statistical significance using the general linear model (GLM) procedure of the Statistical Analysis System (SAS Institute, Cary, NC). All data were subjected to oneway analysis of variance and, when appropriate, a multiple-range test was conducted by Fisher's least significant difference (LSD) at $P \leq 0.01$.

Sequence analyses. The EST sequence representing a part of the $C r 811$ gene was retrieved from GenBank (JK747455). Based on this sequence, primer pair g/u (Fig. 1 and Table 1) was designed and used to amplify a genomic fragment. The PCR product was sequenced using both primers $g$ and $u$. Genome walking primers were designed based on this sequence information. After genome walking, the genomic sequence including JK747455 and its $5^{\prime}$ and $3^{\prime}$ regions was obtained by manually assembling the sequences of the overlapped fragments. Primers specific to the $5^{\prime}$ and $3^{\prime}$ ends of the assembled sequence were designed and used to amply fragments from cDNA synthesized from RNA of P5. The PCR products were sequenced and the open reading frames (ORF) predicted using the online program ORF Finder (http://www.ncbi.nlm.nih.gov/gorf/ gorf.html). The coding sequence was identified according to the

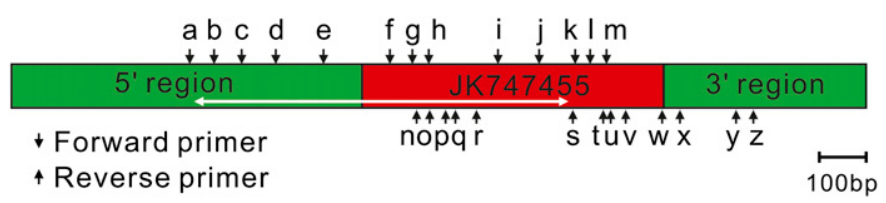

Fig. 1. Diagram of the genomic region of the Cr811 gene. JK747455, GenBank accession number of the expressed sequence tag that is a part of $\mathrm{Cr} 811$; $5^{\prime}$ region and $3^{\prime}$ region, sequences obtained by genome walking; a to $\mathrm{z}$, primers whose sequences are listed in Table 1 . The white line denotes the sequenced cDNA. 
criteria defined by Min et al. (28). Similarity searches of nucleic acid and deduced protein sequences of $\mathrm{Cr} 811$ were performed using the Basic Local Alignment Search Tool (BLAST) against the National Center for Biotechnology Information (NCBI) database unless otherwise specified. Other sequence analyses were performed using the appropriate software as accessed from http://ca. expasy.org.

Genome walking. Genome walking was conducted based on the genomic DNA from the P5 single-spore isolate using the APAgene Gold Genome Walking Kit (Bio S\&T, Montreal, QC, Canada). The gene specific primers required by the protocol were primers $\mathrm{p}, \mathrm{o}$, and $\mathrm{n}$ for $5^{\prime}$ and $\mathrm{k}, 1$, and $\mathrm{m}$ for $3^{\prime}$ (Fig. 1; Table 1). After the second nested PCR, three bands of each of $5^{\prime}$ and $3^{\prime}$ walkings were TA cloned and sequenced using the M13 forward primer.

Dot blotting and Southern analysis. Dot blotting and Southern analysis were performed with a Dig DNA Labeling and Detection Kit (Roche Applied Science, Indianapolis, IN). For dot blotting, $10 \mu \mathrm{l}$ of genomic DNA ( $500 \mathrm{ng} / \mu \mathrm{l})$ from each of the singlespore isolates belonging to the five pathotypes was boiled in water for $5 \mathrm{~min}$ to denature the DNA. After quickly chilling on ice, $2-\mu \mathrm{l}$ aliquots of the solution were arrayed in duplicate on the positively charged nylon membranes (Roche Applied Science). For Southern analysis, $2 \mu \mathrm{g}$ of genomic DNA from the P5 single-spore isolate was digested with XhoI (New England Biolabs, Ipswich, MA) at $37^{\circ} \mathrm{C}$ for $4 \mathrm{~h}$. The digests were resolved on a $1 \%$ agarose gel and transferred onto the nylon membrane. Membranes for both dot blotting and Southern analysis were baked at $80^{\circ} \mathrm{C}$ for $2 \mathrm{~h}$ and then hybridized with a Cr811-specific (dot blot and Southern) and an Actin1-specific (dot blot) probe labeled with digoxigenin. Probes were synthesized from $1 \mu \mathrm{g}$ and $200 \mathrm{ng}$ of PCR products amplified from the genomic DNA of the P5 single-spore isolate using the primer pair g/u (Fig. 1; Table 1) and ActF/ActR (Table 1), respectively. The absence of the XhoI cutting site within the probe-specific genomic region was confirmed by a manual search. Hybridizations were performed overnight at $37^{\circ} \mathrm{C}$. The posthybridization washes were performed twice for $5 \mathrm{~min}$ at $22^{\circ} \mathrm{C}$ with $2 \times \mathrm{SSC}(1 \times \mathrm{SSC}$ is $150 \mathrm{mM} \mathrm{NaCl}$ and $15 \mathrm{mM}$ sodium citrate) and $0.1 \%$ SDS and twice for $15 \mathrm{~min}$ at $22^{\circ} \mathrm{C}$ with $0.5 \times$ SSC and $0.1 \%$ SDS. The hybridization signal was detected using anti-dig antibodies and visualized with NBT/BCIP. The time of color development was $10 \mathrm{~min}$ for dot blotting and approximately $2 \mathrm{~h}$ for Southern.

Plant inoculation. Seeds of host plants were surface-sterilized in $1 \%$ sodium hypochlorite for $5 \mathrm{~min}$, washed with deionized water, and germinated on moistened filter paper for 7 days. The resulting seedlings were inoculated with the resting spore suspension $\left(1 \times 10^{7}\right.$ spores/ml) using the root-dipping method as described by Strelkov et al. (40). The inoculated plants were transferred into 2-liter plastic pots containing autoclaved Sunshine mix \#4 soil (Sun Gro Horticulture, Vancouver, BC, Canada). The pots were kept in a greenhouse maintained at $24^{\circ} \mathrm{C} / 18^{\circ} \mathrm{C}$ (day/night) with a 16-h photoperiod, and watered from the bottom every second day with tap water at pH 6.4 (adjusted with

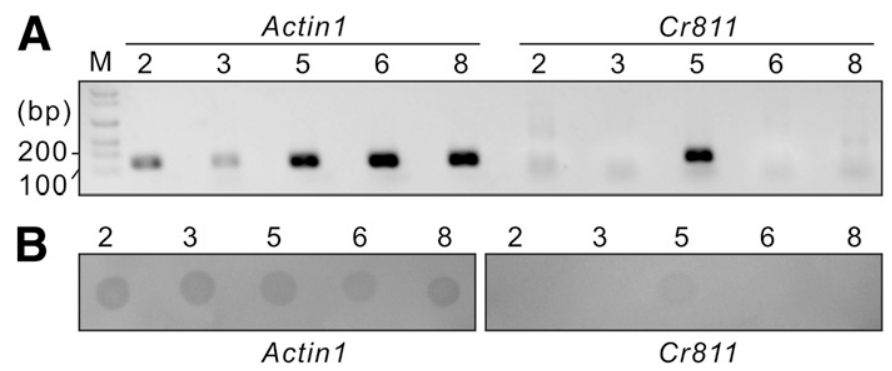

Fig. 2. Identification and confirmation of the presence of the Cr811 gene solely in the pathotype 5 single-spore isolate of Plasmodiophora brassicae. Lanes 2 to 8, DNA from the five pathotypes. A, Polymerase chain reaction identification of Cr811. Actinl and Cr811, primer pairs ActF/ActR for the Actinl gene and f/q for Cr811. M, DNA marker. B, Dot blot analysis. The probe is specific to Actin1 (left) or Cr811 (right).
$\mathrm{HCl})$. For investigating the in planta expression of $\mathrm{Cr} 811$, root samples were collected at $0,5,7,14,21,28$, and 35 days after inoculation (dai). For pathotype determination on the Williams (42) differential hosts, the experiment was conducted as a randomized complete block design with four pots (replications) per treatment and 12 plants per pot. The clubroot assessment on individual plants was conducted at 35 dai using a 0 to 3 rating scale. The disease index of all plants in each pot was calculated as described by Strelkov et al. (40). Microscopic examination of the cortex of '45H26' and '45H29' at 35 dai was conducted with a Zeiss AX10 microscope (Carl Zeiss, Oberkochen, Germany).

\section{RESULTS}

The $C r 811$ gene is present in the pathotype 5 isolate but not in other isolates tested. Against genomic DNA from isolates representing five $P$. brassicae pathotypes (P2, P3, P5, P6, and $\mathrm{P} 8$ ), PCR analysis was conducted using 118 pairs of primers, with each of primer pairs specific to a gene encoding a protein or represented by an EST. Among these primers, the primer pair f/q amplified a band from the P5 isolate but not from isolates of the other four pathotypes (Fig. 2A). This primer pair was specific to a previously reported EST (JK747455) that is hereafter named $\mathrm{Cr} 811$ in this study. The exclusive presence of $\mathrm{Cr} 811$ in the isolate of P5 was confirmed by an alternative primer pair $\mathrm{g} / \mathrm{u}$ as well as all possible combinations between forward primers a, b, c, d, and e and reverse primers $\mathrm{v}, \mathrm{w}, \mathrm{x}, \mathrm{y}$, and $\mathrm{z}$ (data not shown). Using three pairs of qPCR primers, $\mathrm{h} / \mathrm{r}, \mathrm{i} / \mathrm{s}$, and $\mathrm{j} / \mathrm{t}$, reverse transcription (RT)-PCR was conducted against RNA from the isolates representing the five pathotypes. Transcript could be detected from the P5 isolate but not from the other isolates, indicating the exclusiveness of $\mathrm{Cr} 811$ in RNA of the P5 isolate (data not shown). The PCR and RT-PCR described above were repeated against DNA and RNA extracted from galls produced on 'Westar' inoculated with resting spores from the original galls. A band or signal was produced only from the P5 isolate, indicating the vertical inheritance of $\mathrm{Cr} 811$ in this isolate (data not shown).

Dot blotting using the Actinl fragment as a probe resulted in signals with similar intensities from all the five isolates. In contrast, the $C r 811$ probe produced a signal from the DNA of the P5 isolate and no signal from isolates of the other pathotypes (Fig. 2B), suggesting that these other isolates lack the complete probe-specific sequence in the $C r 811$ region.

Cr811 encodes a putative peptide with unknown function. The PCR product of primer pair g/u against genomic DNA of the P5 isolate was sequenced and TA cloned. The resulting sequence had one base pair difference with the region between the two primers on the cDNA clone JK747455. After genome walking, an 1,827-bp sequence including the $5^{\prime}$ region, the sequence flanking JK747455 and the 3 ' region was obtained. This sequence was submitted to GenBank with the accession number KJ867531. A Blastn search with this sequence as a query did not produce any hit other than JK747455. Against cDNA from the P5 isolate, a PCR product was obtained using primer pair a/s and its sequence was identical with the region flanked by the two primers on the genomic sequence, indicating that this fragment contains a partial reading frame without introns. The cDNA sequence was submitted to GenBank with the accession number KJ867530. Using the ORF Finder software, a 492-bp coding sequence was predicted that is located at nucleotides 281-772 on KJ867530. A Blastx search with this cDNA sequence as a query produced three hits with an E-value smaller than 1 and aligned sequences larger than 150 amino acids: a hypothetical protein (RO3G_17302) from Rhizopus delemar with $30 \%$ identity and an E-value $=1 \times 10^{-10}$, an uncharacterized protein (UHOR_12604) from Ustilago hordei with $27 \%$ identity and an E-value $=2 \times 10^{-4}$, and an uncharacterized protein (CCA27723) from Albugo laibachii with $22 \%$ identity and an E-value $=0.011$. The ORF finder-predicted coding sequence was in-frame with but 
shorter at the $5^{\prime}$ end than the portion of the cDNA sequence being aligned with each of the three Blastx hits. This suggests that the predicted coding sequence is the $3^{\prime}$ part of a real ORF. Since all Blast hits encode uncharacterized proteins, no biological function can be inferred for $\mathrm{Cr} 811$.

Cr811 is present as a single copy in the $P$. brassicae genome. Given the fact that it is almost impossible to obtain pure $P$. brassicae DNA without contamination from other organisms, experiments were designed to confirm the $P$. brassicae-origin of Cr811. One milliliter of gall slurry that contained $3.75 \times 10^{6}$ resting spores was prepared from the P5-infected 'Westar' and cultured in $20 \mathrm{ml}$ of $\mathrm{LB}$ medium at $37^{\circ} \mathrm{C}$. After $16 \mathrm{~h}$, the medium became cloudy, indicating the proliferation of bacteria. Total DNA was extracted from the culture pellet. Against this DNA sample and the DNA from infected roots collected at 35 dai of ' $45 \mathrm{H} 26$ ' and '45H29' with the P5 isolate, qPCR analysis was conducted with the primer pair h/r for $C r 811$ and primer pair ActF/ActR for Actinl as a control. The $\triangle \mathrm{CT}$ values between $C r 811$ and Actinl in the three DNA samples were not significantly different (Fig. 3A), indicating that the amount of $C r 811$ DNA is proportional to the $P$. brassicae biomass represented by the CT value of Actin1, but not to the amount of total DNA. The data confirm that $C r 811$ is not present in bacteria associated with $P$. brassicae or resident in the soil, and is most likely in the $P$. brassicae genome.

Southern analysis was conducted to investigate the copy number of $C r 811$. A hybridization signal was detected from a single band of P5 DNA cut with XhoI, indicating the single-copy nature of $\mathrm{Cr} 811$ in the genome of the P5 isolate.

Expression of $\mathrm{Cr} 811$ is up-regulated in infected plants. During the infection of the susceptible cultivar $45 \mathrm{H} 26$, the expression levels of $\mathrm{Cr} 811$ in general were lower than those of the control gene Actinl. At 5 dai, the expression of $C r 811$ was just $1 \%$ that of Actin1. The expression level increased at 7 dai and reached a peak at 14 dai, when it was $80 \%$ that of Actin1. After 14 dai, the expression decreased (Fig. 4A). In the resistant cultivar $45 \mathrm{H} 29$, a primary peak of expression was observed at 5 dai, in which the expression of $\mathrm{Cr} 81 \mathrm{l}$ was 1.5 times that of Actin1. The expression declined to a low level until 21 dai. At 28 and 35 dai, the expression increased dramatically to 600 times higher than Actinl (Fig. 4B). The roots of ' $45 \mathrm{H} 26$ ' and ' $45 \mathrm{H} 29$ ' at 35 dai were sampled and examined microscopically. The galls of '45H26' were full of resting spores. By contrast, no typical galls were obtained on ' $45 \mathrm{H} 29$ '. Nonetheless, plasmodia were observed in the roots of '45H29' (Fig. 4C).

Cr811 distinguished a field isolate of P5 from two other field isolates representing $\mathbf{P 3}$ and P8. Galls caused by natural infection were collected from different field locations in Alberta, Canada. Three field isolates were obtained from the galls and evaluated by PCR analysis with the primer pairs g/u and ActF/ActR. A band was amplified by $\mathrm{g} / \mathrm{u}$ from one field isolate but not from the other two isolates (Fig. 5A). The pathotype identities of these three isolates were determined by their reactions on the Williams' differential hosts and ECD hosts (Supplementary Table 1; Fig. 5B). The isolate that was able to produce the $\mathrm{g} / \mathrm{u}$ band was classified as P5 on Williams hosts and 16/6/8 on ECD hosts, which are identical to the pathotyping results of the single spore isolate ORCA-ss4. The other two isolates were classified as P3 or P8 on Williams' hosts and $16 / 15 / 12$ or $16 / 15 / 8$ on the ECD hosts. This result suggests that Cr811 may have potential as a marker to distinguish P5 or 16/6/8 from other pathotypes of $P$. brassicae.

\section{DISCUSSION}

Differences in virulence among $P$. brassicae populations have been studied using various sets of differential hosts, with isolates of the pathogen classified into pathotypes (39). Although the molecular basis for differential classification of pathotypes is largely unknown, a notion accepted by most researchers is that the difference between pathotypes ultimately reflects differences in their genetic makeup, i.e., either the presence or absence of certain pathogenicity-related genes, or differential expression of those genes. In the current study, $\mathrm{Cr} 811$ was identified only in P5 isolates. The identity of $\mathrm{Cr} 81 \mathrm{l}$ as a gene rather than a fragment of noncoding DNA is supported by that facts that it has been repeatedly isolated from mRNA preparations and that it showed regulation patterns independent from the pathogen biomass. This gene was first identified by suppression subtractive hybridization between infected and healthy canola roots (14). In a previous study, the expression of Cr811 in 'Westar' was found to be higher in secondary zoospores than primary zoospores (15), suggesting that it has some role in the secondary stage of clubroot infection.

In the current study, we did not intend to define the types of spores but tried to monitor the $\mathrm{Cr} 811$ expression at different infection stages with a time-course. Nevertheless, the increased expression of Cr811 in ' $45 \mathrm{H} 26$ ' from 0 to 14 dai observed in the current study is consistent with the findings of Feng et al. (15), indicating that the in planta regulation of $\mathrm{Cr} 811$ in various susceptible genotypes is similar during the early stages of infection. On the other hand, regulation of $\mathrm{Cr} 811$ expression at later infection stages in the susceptible genotype $45 \mathrm{H} 26$ was dramatically different from that in the resistant genotype $45 \mathrm{H} 29$. This may indicate that $\mathrm{Cr} 811$ is specifically up-regulated in secondary plasmodia, similar to the $Y 10$ gene (21) and the PbBrip9 and PbCC249 genes (37) that have been found to be strongly expressed at stages of disease development corresponding to the occurrence of secondary plasmodia. In both '45H26' and '45H29', primary infection and secondary infection are essentially similar in manner and timing. In both genotypes, secondary infection is established at approximately 14 dai. The CT values of the $C r 811$ transcript in resistant and susceptible genotypes were similar at 14 dai because similar numbers of secondary plasmodia were present in both genotypes. After 14 dai, however, the secondary plasmodia in the susceptible genotype matured and large numbers of resting spores were formed, resulting in a much lower CT value for Actin1 than in the resistant genotype. In the resistant genotype, no resting spores were formed and secondary plasmodia continued to accumulate in the root cortex. This was observed not only in '45H29' in the current study, but also in other resistant genotypes $(10,23)$ and even in nonhost plants (18). In resistant plants $P$. brassicae cannot progress further than the plasmodial stage, which results in a relatively high number of plasmodia that build up in the cortex. By contrast, the pathogen progresses beyond this initial plasmodial stage in susceptible plants
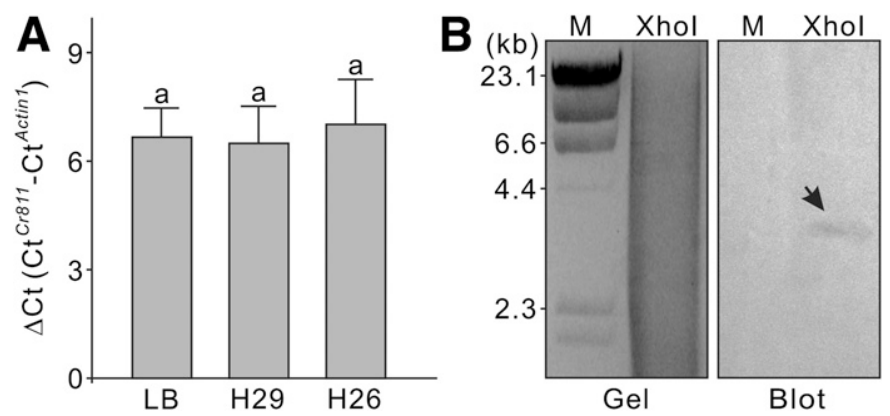

Fig. 3. Confirmation of the occurrence of the $C r 811$ gene in the genome of Plasmodiophora brassicae pathotype 5 as a single copy. A, Quantitative polymerase chain reaction analysis of DNA derived from P5-infected plants at 35 days after inoculation. LB, overnight LB culture of gall slurry prepared from canola cultivar Westar; $\mathrm{H} 26$ and $\mathrm{H} 29$, and galls collected from canola cultivars $45 \mathrm{H} 26$ and $45 \mathrm{H} 29$, respectively. Means in the plot marked by the same letter do not differ based on Fisher's least significant difference test at $P \leq 0.01(n=3)$. B, Southern analysis. Genomic DNA from the P5 singlespore isolate was digested with XhoI and hybridized with a PCR fragment specific to the $C r 811$ gene. M, DNA marker. The arrow indicates that signal is evident from a single band. 
and, therefore, fewer plasmodia are seen in the cortex (23). If $\mathrm{Cr} 811$ is up-regulated in secondary plasmodia and down-regulated in resting spores, the different numbers of resting spores and plasmodia in '45H26' and '45H29' could explain the expression patterns observed in Figure 4A and B.

A preliminary genomic study indicated that $P$. brassicae genes are rich in spliceosomal introns (5), a finding that was supported by functional studies of individual $P$. brassicae genes. For example, the serine protease gene $P R O 1$ contains eight introns within the 1,847bp ORF (13). By contrast, the 492-bp reading frame of $\mathrm{Cr} 811$ does not contain any introns. This sequence may represent one of the exons in the intron-containing Cr811 gene or, on the other hand, Cr811 may not contain any introns. These possibilities will be examined in a subsequent gene functional study.

The evolution of pathogens and their hosts is often interpreted as an arms race, in which both hosts and pathogens can respond to changes that occur in their opponents. This arms race is accelerated after a pathosystem is moved from a natural ecosystem to agroecosystem (2). New pathotypes or races are generated in the pathogen population at a higher speed, usually achieved by mutations in single
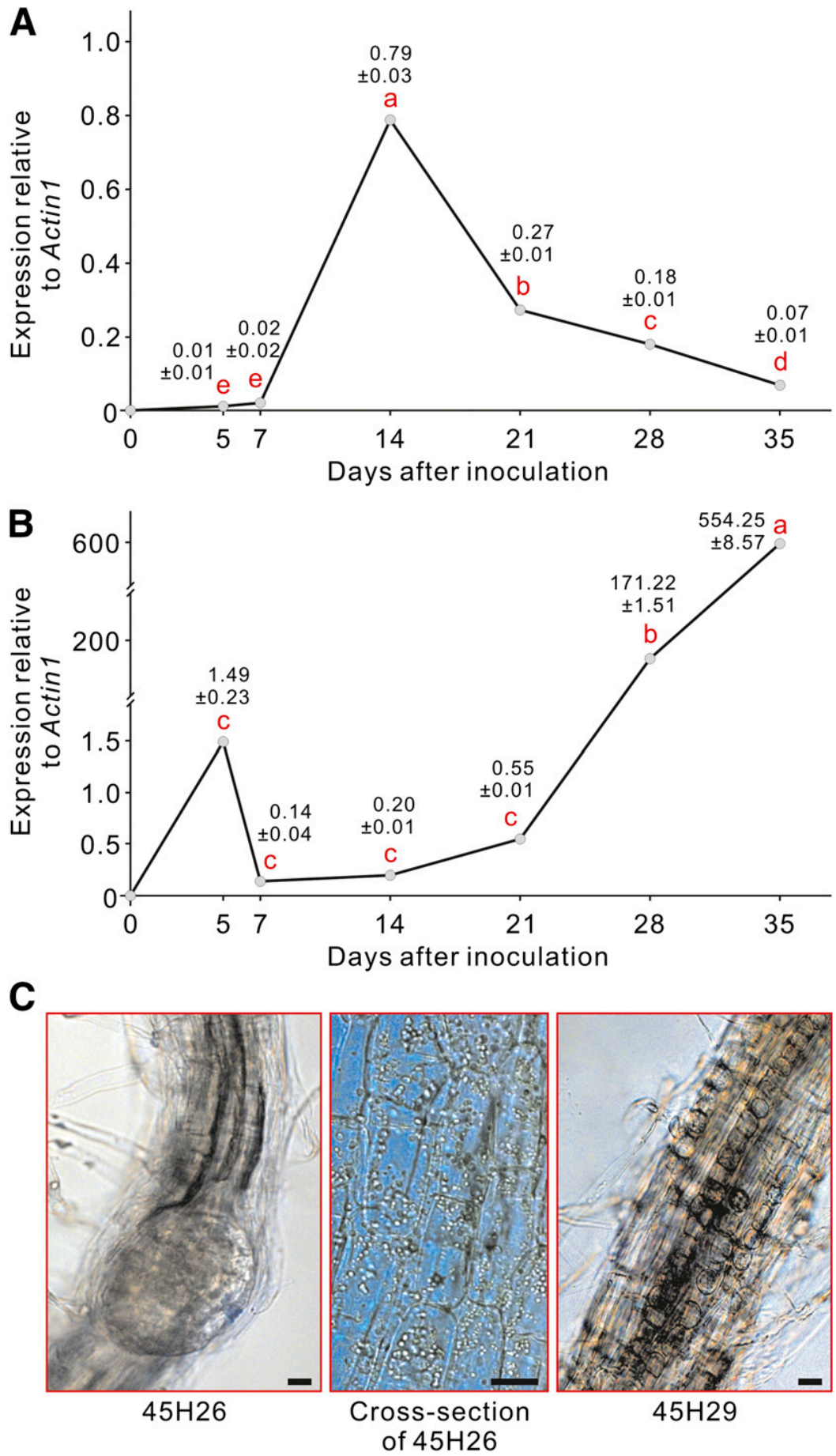

Fig. 4. Expression of $\mathrm{Cr} 811$ during plant infection. Canola cultivars A, $45 \mathrm{H} 26$ and $\mathbf{B}, 45 \mathrm{H} 29$ were inoculated with pathotype 5 of Plasmodiophora brassicae and the infected root samples were collected at 0 to 35 days after inoculation. The primers used for quantitative polymerase chain reaction analysis were ActF/ActR for the Actinl gene and h/r for Cr811. Means \pm standard deviation in the plot annotated by the same letter do not differ based on Fisher's least significant difference test at $P \leq 0.01(n=3)$. C, Root cortex of canola cultivars $45 \mathrm{H} 26$ and $45 \mathrm{H} 29$ at 35 days after inoculation. Bars $=10 \mu \mathrm{m}$. 
effector genes (8). In addition, horizontal gene transfer (HGT) also provides a means for pathogens to create new virulent forms (races or pathotypes) or to broaden their host range $(27,31)$. HGT is very common in protists $(1,34)$ and thus $P$. brassicae may be a HGT amiable species. Phylogenetic and systemic studies suggested that clubroot is a disease of cultivation (9) and $P$. brassicae likely became a pathogen of crucifers by means of cross-kingdom host shifts (30), increasing the likelihood that HGT has been involved in the coevolution of $P$. brassicae and cruciferous plants. The amenability of $P$. brassicae for HGT has been supported by the successful genetic transformation of this pathogen (16) and by the bservation that the same EST sequences were identified from both $P$. brassicae (6) and the host plants (24). The ability to accept foreign DNA may also be related to the unusual variability seen in $P$. brassicae field populations $(26,38,43)$. In the current study, the presence of the $C r 811$ gene in P5 isolates of P. brassicae and its complete absence in isolates representing other pathotypes suggests that this gene maybe a result of HGT. Furthermore, the absence of an intron in the 492-bp reading frame strengthens the possibility that $\mathrm{Cr} 811$ is a result of HGT.

The relationship between diversity in pathogenicity (races and pathotypes) and DNA polymorphisms in $P$. brassicae populations has been studied, mainly by RAPD marker analysis $(4,11,25,29,44)$. Yano et al. (44) reported that RAPD analysis was able to clearly differentiate Williams' race 9 populations from populations of other races. Similarly, Manzanares-Dauleux et al. (25) developed an RAPD-derived SCAR marker specific to P1, as classified on the differentials of Somé et al. (38) of $P$. brassicae. The $C r 811$ gene identified in the current study may prove useful as another marker to differentiate $P$. brassicae pathotypes. Nonetheless, the specificity of this marker for P5 will have to be confirmed by testing a larger collection of isolates with broader geographic origins. With optimized techniques for $P$. brassicae DNA purification and single-spore isolation, along with the accumulation of publicly available $P$. brassicae sequences, more genetic markers able to differentiate pathotypes of the parasite are expected to be found.

In summary, the current study indicates that the $\mathrm{Cr} 811$ gene is present in several P5 isolates of $P$. brassicae, but not in isolates representing P2, P3, P6, or P8, and therefore may serve as a genetic marker to identify P5 from isolates of other pathotypes. It has not escaped our notice that the exclusive presence of $\mathrm{Cr} 811$ in the tested P5 isolates provides a useful tool in studies on pathotype dynamics under the selection pressure of various resistance genes. The gene is highly expressed in secondary plasmodia, suggesting a potential role in pathogenicity during this stage of infection.

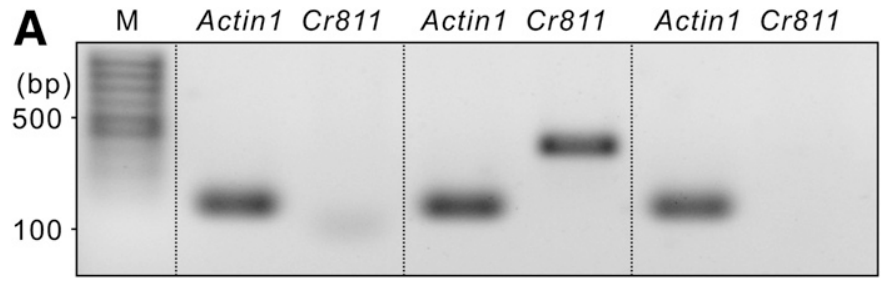

B

$\begin{array}{cccc}\begin{array}{c}\text { Pathotype } \\ \text { (Williams) }\end{array} & \text { P3 } & \text { P5 } & \text { P8 } \\ \begin{array}{c}\text { Pathotype } \\ \text { (ECD) }\end{array} & 16 / 15 / 12 & 16 / 6 / 8 & 16 / 15 / 8\end{array}$

Fig. 5. Identification of pathotype 5 in three field isolates of Plasmodiophora brassicae $\mathbf{A}$, by polymerase chain reaction analysis using $\mathrm{Cr} 811$-specific primers and $\mathbf{B}$, by pathogenicity tests on the Williams and the European clubroot differential (ECD) hosts. Actin1 and $\mathrm{Cr} 811$, primer pairs ActF/ActR for the Actin1 gene and g/u for $\mathrm{Cr} 811$; M, DNA marker. Pathogenicity data are derived from four replications of the experiment, each consisting of 12 plants.

\section{ACKNOWLEDGMENTS}

We thank the Alberta Crop Industry Development Fund, Canola Agronomic Research Program, and the Canola Sciences Cluster for funding support.

\section{LITERATURE CITED}

1. Andersson, J. O. 2005. Lateral gene transfer in eukaryotes. Cell. Mol. Life Sci. 62:1182-1197.

2. Brown, J. K., and Tellier, A. 2011. Plant-parasite coevolution: Bridging the gap between genetics and ecology. Annu. Rev. Phytopathol. 49: 345-367.

3. Buczacki, S. T., Toxopeus, H., Mattusch, P., Johnston, T. D., Dixon, G. R., and Hobolth, L. A. 1975. Study of physiologic specialization in Plasmodiophora brassicae: Proposals for attempted rationalization through an international approach. Trans. Br. Mycol. Soc. 65:295-303.

4. Buhariwalla, H., Greaves, S., Magrath, R., and Mithen, R. 1995. Development of specific PCR primers for amplification of polymorphic DNA from the obligate root pathogen Plasmodiophora brassicae. Physiol. Mol. Plant Pathol. 47:83-94.

5. Bulman, S., Ridgway, H. J., Eady, C., and Conner, A. J. 2007. Intronrich gene structure in the intracellular plant parasite Plasmodiophora brassicae. Protist 158:423-433.

6. Bulman, S., Siemens, J., Ridgway, H. J., and Conner, A. J. 2006. Identification of genes from the obligate intracellular plant pathogen, Plasmodiophora brassicae. FEMS Microbiol. Lett. 264:198-204.

7. Cao, T., Manolii, V. P., Hwang, S. F., Howard, R. J., and Strelkov, S. E. 2009. Virulence and spread of Plasmodiophora brassicae [clubroot] in Alberta, Canada. Can. J. Plant Pathol. 31:321-329.

8. Dickinson, M. 2003. Molecular Plant Pathology. BIOS Scientific Publishers, New York.

9. Dixon, G. R. 2009. The occurrence and economic impact of Plasmodiophora brassicae and clubroot disease. J. Plant Growth Regul. 28:194-202.

10. Donald, E. C., Jaudzems, G., and Porter, I. J. 2008. Pathology of cortical invasion by Plasmodiophora brassicae in clubroot resistant and susceptible Brassica oleracea hosts. Plant Pathol. 57:201-209.

11. Fähling, M., Graf, H., and Siemens, J. 2003. Pathotype separation of Plasmodiophora brassicae by the host plant. J. Phytopathol. 151:425-430.

12. Feng, J., Hwang, R., Chang, K. F., Hwang, S. F., Strelkov, S. E., Gossen, B. D., and Zhou, Q. 2010. An inexpensive method for extraction of genomic DNA from fungal mycelia. Can. J. Plant Pathol. 32:396-401.

13. Feng, J., Hwang, R., Hwang, S. F., Strelkov, S. E., Gossen, B. D., Zhou, Q., and Peng, G. 2010. Molecular characterization of a serine protease Pro1 from Plasmodiophora brassicae that stimulates resting spore germination. Mol. Plant Pathol. 11:503-512.

14. Feng, J., Hwang, S. F., and Strelkov, S. E. 2012. Analysis of expressed sequence tags derived from a compatible Plasmodiophora brassicae-canola interaction. Can. J. Plant Pathol. 34:562-574.

15. Feng, J., Hwang, S. F., and Strelkov, S. E. 2013. Assessment of gene expression profiles in primary and secondary zoospores of Plasmodiophora brassicae by dot blot and real-time PCR. Microbiol. Res. 168:518-524.

16. Feng, J., Hwang, S. F., and Strelkov, S. E. 2013. Genetic transformation of the obligate parasite Plasmodiophora brassicae. Phytopathology 103: 1052-1057.

17. Feng, J., Hwang, S. F., and Strelkov, S. E. 2013. Studies into primary and secondary infection processes by Plasmodiophora brassicae on canola. Plant Pathol. 62:177-183.

18. Feng, J., Xiao, Q., Hwang, S. F., Strelkov, S. E., and Gossen, B. D. 2012. Infection of canola by secondary zoospores of Plasmodiophora brassicae produced on a nonhost. Eur. J. Plant Pathol. 132:309-315.

19. Hwang, S. F., Howard, R. J., Strelkov, S. E., Gossen, B. D., and Peng, G. 2014. Management of clubroot (Plasmodiophora brassicae) on canola (Brassica napus) in western Canada. Can. J. Plant Pathol. 36(suppl.): 49-65.

20. Hwang, S. F., Strelkov, S. E., Feng, J., Gossen, B. D., and Howard, R. J. 2012. Plasmodiophora brassicae: A review of an emerging pathogen of the Canadian canola (Brassica napus) crop. Mol. Plant Pathol. 13:105-113.

21. Ito, S., Ichinose, H., Yanagi, C., Tanaka, S., Kameya-Iwaki, M., and Kishi, F. 1999. Identification of an in planta-induced mRNA of Plasmodiophora brassicae. J. Phytopathol. 147:79-82.

22. Jones, D. R., Ingram, D. S., and Dixon, G. R. 1982. Factors affecting tests for differential pathogenicity in populations of Plasmodiophora brassicae. Plant Pathol. 31:229-238.

23. Kroll, T. K., Lacy, G. H., and Moore, L. D. 1983. A quantitative description of the colonization of susceptible and resistant radish plants by Plasmodiophora brassicae. J. Phytopathol. 108:97-105. 
24. Lee, S. C., Lim, M. H., Kim, J. A., Lee, S. I., Kim, J. S., Jin, M., Kwon, S. J., Mun, J. H., Kim, Y. K., Kim, H. U., Hur, Y., and Park, B. S. 2008. Transcriptome analysis in Brassica rapa under the abiotic stresses using Brassica 24K oligo microarray. Mol. Cells 26:595-605.

25. Manzanares-Dauleux, M. J., Barret, P., and Thomas, G. 2000. Development of a pathotype specific SCAR marker in Plasmodiophora brassicae. Eur. J. Plant Pathol. 106:781-787.

26. Manzanares-Dauleux, M. J., Divaret, I., Baron, F., and Thomas, G. 2001. Assessment of biological and molecular variability between and within field isolates of Plasmodiophora brassicae. Plant Pathol. 50:165-173.

27. Mehrabi, R., Bahkali, A. H., Abd-Elsalam, K. A., Moslem, M., M'Barek, S. B., Gohari, A. M., Jashni, M. K., Stergiopoulos, I., Kema, G. H., and de Wit, P. J. 2011. Horizontal gene and chromosome transfer in plant pathogenic fungi affecting host range. FEMS Microbiol. Rev. 35:542-554.

28. Min, X. J., Butler, G., Storms, R., and Tsang, A. 2005. OrfPredictor: Predicting protein-coding regions in EST-derived sequences. Nucleic Acids Res. 33(suppl. 2):W677-W680.

29. Möller, M., and Harling, R. 1996. Randomly amplified polymorphic DNA (RAPD) profiling of Plasmodiophora brassicae. Lett. Appl. Microbiol. 22:70-75.

30. Neuhauser, S., Kirchmair, M., Bulman, S., and Bass, D. 2014. Crosskingdom host shifts of phytomyxid parasites. BMC Evol. Biol. 14:33.

31. Ochman, H., Lawrence, J. G., and Groisman, E. 2000. Lateral gene transfer and the nature of bacterial innovation. Nature 405:299-304

32. Peng, G., Lahlali, R., Hwang, S. F., Pageau, D., Hynes, R. K., McDonald, M. R., Gossen, B. D., and Strelkov, S. E. 2014. Crop rotation, cultivar resistance, and fungicides/biofungicides for managing clubroot (Plasmodiophora brassicae) on canola. Can. J. Plant Pathol. 36(suppl.):99-112.

33. Rahman, H., Peng, G., Yu, F., Falk, K. C., Kulkarni, M., and Selvaraj, G. 2014. Genetics and breeding for clubroot resistance in Canadian spring canola (Brassica napus L.). Can. J. Plant Pathol. 36(suppl.):122-134.
34. Richards, T. A., Hirt, R. P., Williams, B. A. P., and Embley, T. M. 2003. Horizontal gene transfer and the evolution of parasitic protozoa. Protist 154:17-32.

35. Sambrook, J., and Russell, D. W. 2001. Molecular Cloning: A Laboratory Manual. 3rd Ed. Cold Spring Harbor Laboratory Press, Cold Spring Harbor, New York.

36. Schmittgen, T. D., and Livak, K. J. 2008. Analyzing real-time PCR data by the comparative $C_{\mathrm{T}}$ method. Nat. Protoc. 3:1101-1108.

37. Siemens, J., Graf, H., Bulman, S., In, O., and Ludwig-Müller, J. 2009. Monitoring expression of selected Plasmodiophora brassicae genes during clubroot development in Arabidopsis thaliana. Plant Pathol. 58:130-136.

38. Somé, A., Manzanares-Dauleux, M. J., Laurens, F., Baron, F., Thomas, G., and Rouxel, F. 1996. Variation for virulence on Brassica napus L. amongst Plasmodiophora brassicae collections from France derived from single-spore isolates. Plant Pathol. 45:432-439.

39. Strelkov, S. E., and Hwang, S. F. 2014. Clubroot in the Canadian canola crop: 10 years into the outbreak. Can. J. Plant Pathol. 36(suppl.):27-36.

40. Strelkov, S. E., Manolii, V. P., Cao, T., Xue, S., and Hwang, S. F. 2007. Pathotype classification of Plasmodiophora brassicae and its occurrence in Brassica napus in Alberta, Canada. J. Phytopathol. 155:706-712.

41. Strelkov, S. E., Tewari, J. P., Smith, E., and Smith-Degenhardt, E. 2006. Characterization of Plasmodiophora brassicae populations from Alberta, Canada. Can. J. Plant Pathol. 28:467-474.

42. Williams, P. H. 1966. A system for the determination of races of Plasmodiophora brassicae that infect cabbage and rutabaga. Phytopathology 56:624-626.

43. Xue, S., Cao, T., Howard, R. J., Hwang, S. F., and Strelkov, S. E. 2008. Isolation and variation in virulence of single-spore isolates of Plasmodiophora brassicae from Canada. Plant Dis. 92:456-462.

44. Yano, S., Tanaka, S., Ito, S., and Kameya-Iwaki, M. 1997. Variations of random amplified polymorphic DNA (RAPD) patterns among field populations of Plasmodiophora brassicae. Ann. Phytopathol. Soc. Jpn. 63:179-182. 